\title{
Th Subset Balance in Lupus Nephritis
}

\author{
Katsuhisa Miyake, ${ }^{1}$ Mitsuteru Akahoshi, ${ }^{2}$ and Hitoshi Nakashima ${ }^{1}$ \\ ${ }^{1}$ Division of Nephrology and Rheumatology, Department of Internal Medicine, Faculty of Medicine, Fukuoka University, \\ Fukuoka 814-0180, Japan \\ ${ }^{2}$ Department of Medicine and Biosystemic Science, Graduate School of Medical Science, Kyushu University, Fukuoka 812-8582, Japan
}

Correspondence should be addressed to Katsuhisa Miyake, kmiyake@fukuoka-u.ac.jp

Received 27 June 2011; Accepted 5 July 2011

Academic Editor: Brian Poole

Copyright ( $\odot 2011$ Katsuhisa Miyake et al. This is an open access article distributed under the Creative Commons Attribution License, which permits unrestricted use, distribution, and reproduction in any medium, provided the original work is properly cited.

Lupus nephritis, which has various histological patterns and variable clinical outcomes, is one of the most important complications of systemic lupus nephritis (SLE). This pathogenetic mechanism in each histologically different type of lupus nephritis (LN) remains unclear. Although SLE is suggested to be a Th2-driven disease, elevation of both Th1 and Th2 cytokines occurs in both humans and mice, suggesting that SLE is a complex disease driven by different lymphocyte subsets with high heterogeneity of clinical manifestations and organ involvement. Recent findings in LN elucidate an essential role for the Th1, IL-17 producing T cells and Th17 cells in the development of diffuse proliferative lupus nephritis (DPLN), and Th2 cytokine in that of membranous lupus nephritis (MLN). These data support the hypothesis that individual Th1/Th2 balance is one of the critical determinants for histopathology of LN.

\section{Introduction}

Systemic lupus erythematosus (SLE) is an autoimmune disease, which is characterized by tissue deposition of circulating immune complexes leading to release of inflammatory mediators, influx of inflammatory cells, and clinically apparent disease [1]. It is a prototypic systemic disease and has the potential to involve the multiple organ system in contrast to autoimmune diseases such as multiple sclerosis and type 1 diabetes mellitus [2]. The renal involvement, called lupus nephritis (LN), is one of the most serious complications, and shows the phenotypic and histological heterogeneity. In particular, two polar morphologic forms, diffuse proliferative lupus nephritis (DPLN, World Health Organization (WHO) class IV) and membranous lupus nephritis (MLN, WHO class V) are representative of histological findings in LN [3-5]. DPLN is the most common, severe, and important form of LN. Hematuria and proteinuria are present in all DPLN patients with active disease, and the nephrotic syndrome, hypertension, and renal insufficiency are all frequently seen. Affected patients typically have significant hypocomplementemia (especially C3) and elevated anti-DNA levels, especially during active disease [6]. Patients with DPLN usually have an unfavorable prognosis with a high percentage of eventually progressing to a renal failure despite aggressive treatment [7]. On the other hand MLN patients would be predicted to have proteinuria as the most prominent clinical feature and an indolent course similar to that seen with idiopathic membranous glomerulonephritis (MGN). It is intriguing that two polar morphologic forms exit in the same disease, and what causes the morphologic form determination. Human IgG molecules are classified into four IgG subclasses according to the immunologically distinct constant region of the heavy chain [8]. The IgG is the most important Ig isotype in immunopathogenesis for LN, and accordingly, different IgG subclasses have distinct physicochemical and biological properties. Although it should be recalled that glomerular deposited IgG subclasses have a role for determination of morphological form, it was demonstrated that distribution of subclass in glomerular IgG deposition was not associated with the different histological expressions of DPLN and MLN [9] (Figure 1).

It is widely recognized that naive $\mathrm{CD} 4^{+} \mathrm{T}$ cells become activated and differentiate into various effector $\mathrm{T}$ cell subsets after encountering a specific antigen, T helper type 1 (Th1), 


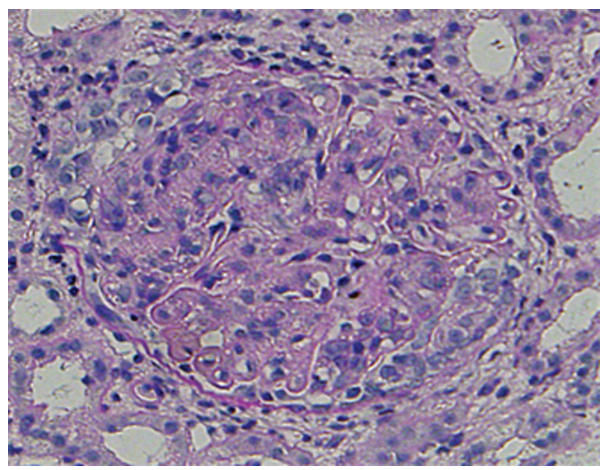

(a)
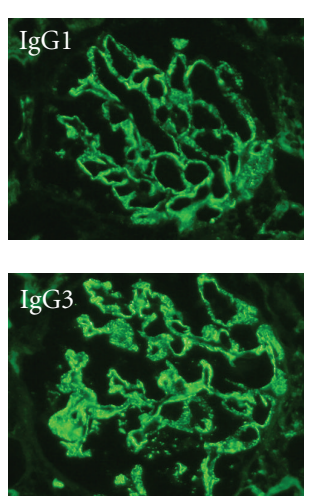

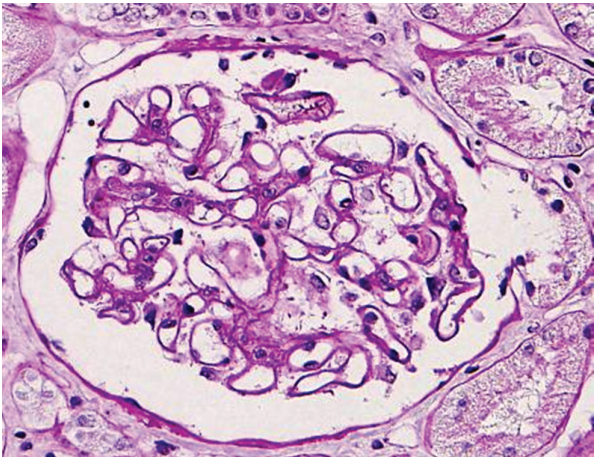

(b)
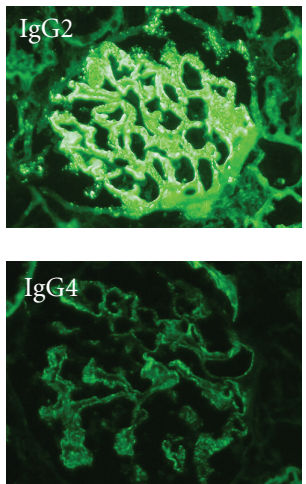

(c)

FIGURE 1: Two polar morphologic forms are representative of histological findings in lupus nephritis. (a) DPLN shows diffuse hypercellularity of endothelial cells and mesangial cells throughout the glomerulus. Peripheral capillary are thickened by subendothelial deposition of immune complex (x400, PAS staining). (b) On the other hand MLN shows generalized diffuse thickening of the peripheral capillary walls without prominent hypercellularity in the glomerulus (x400, PAS staining). (c) Glomerular IgG subclass deposits in a patient with MLN determined by immunofluorescence microscopy (x100). IgG subclass deposition was examined using FITC-conjugated mouse antihuman IgG subclass specific mAbs.

Th2, and Th17 cells, characterized by distinct patterns of cytokine production. Th1 cells produce mainly interferon- $\gamma$ (IFN- $\gamma$ ), interleukin-2 (IL-2), and tumor necrosis factor- $\gamma$ (TNF- $\alpha$ ), and promote cell-mediated immunity. Th2 cells secreting IL-4, IL-5, and IL-10 and are associated with humoral immune responses and induce antibody production [10]. Th17 cells produced IL-17 and drives inflammatory responses. Exaggeration of responses by Th1, Th2, and Th17 cells can induce tissue inflammation and another subset of regulatory $\mathrm{T}$ cells (Treg cells) controls these effector $\mathrm{T}$ cells for maintenance of the immune response and prevention of autoimmunity and tissue inflammation. Various types of Treg cells have been described that mediate these regulatory functions. It has been demonstrated that an imbalance between Th1 and Th2 cytokine production is much concerned with the induction and development of several autoimmune diseases. The polarized situation between Th1 and Th2 cells is established to be important in animal models and human autoimmune diseases [11].

Although a relationship between SLE activity and cytokine productions was abundantly reported, cytokine profiles concerned with LN, especially each histologic phenotype have not been sufficiently discussed. In this review we focus on Th subset, which exerts significant effect on the determination of morphological form in LN.

\section{Th1 Subset}

A large number of studies suggested that SLE is a Th2-driven disease $[12,13]$. However, elevation of both Th1 and Th2 cytokines occurs in both humans and mice suggesting that SLE is a complex disease driven by different lymphocyte subsets [14] with heterogeneity of clinical manifestations and organ involvement.

In human LN, a relationship between histological classification and Th1/Th2 balance was suggested. Immunohistological study for nephritis showed the large number of infiltrating macrophages, Th1 cells, CD40 positive cells, and osteopontin in DPLN, but not in MLN [15]. CD40CD40L interaction and osteopontin function are known to be involved in early Th1-mediated cellular immunity [1618]. IL-12 is a $70 \mathrm{kDa}$ heterodimer (IL12p70) produced by macrophages and dendritic cells (DC). In conjunction with IL-18, it promotes IFN- $\gamma$ production, and leads to polarization of peripheral cells toward a Th1 phenotype. In LN both serum and urinary IL-12p70 elevation was reported 


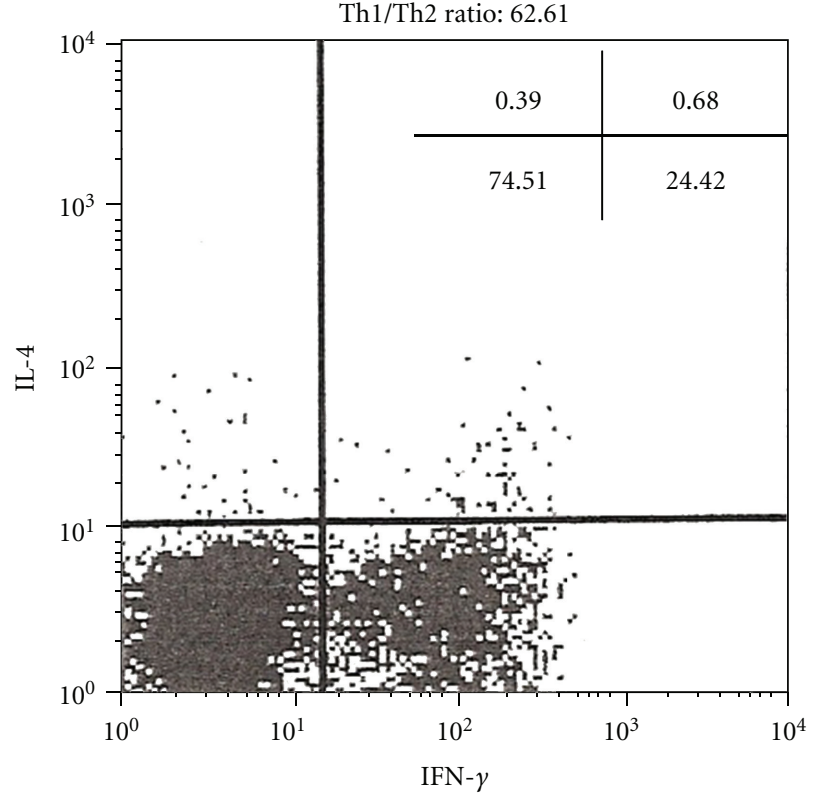

(a)

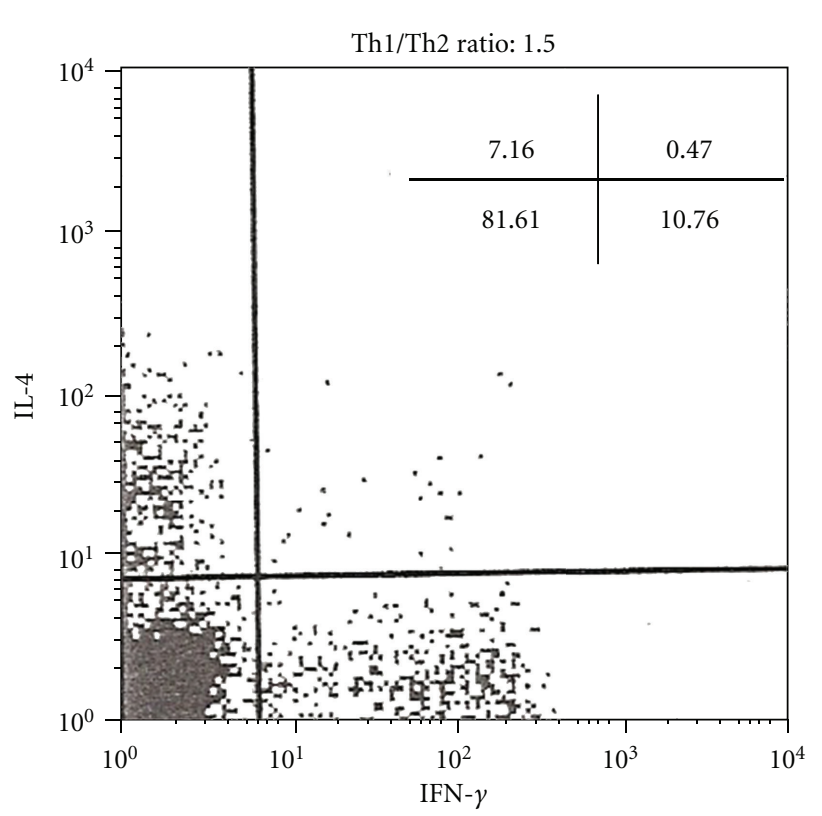

(b)

FIgURE 2: Representative two-color dot plots (anti-IL-4 PE versus anti-IFN- $\gamma$ FITC) from analysis of intracellular cytokines by flow cytometry. Peripheral whole blood samples obtained from individuals were cultured for 4 hours with PMA and ionomycin in the presence of brefeldin A. The activated cells were fixed and stained with anti IFN- $\gamma$ FITC, anti-IL-4 PE, and CD4-PerCP. The cells were then subjected to flow cytometric analysis on a FACScan flow cytometer (Becton Dickinson). Dot plots (a) and (b) are typical examples of FACS histograms which have demonstrated contrastive polarization to the Th1- and Th2-like cytokine responses, respectively. (a) histogram for one SLE patient (age/sex; 48/F) with DPLN. (b) histogram for another SLE patient (age/sex; 21/F) with MLN. The percentage of cells in each of the quadrants are shown in the right upper corners. The values of the Th1/Th2 ratio are shown in the top of each panel.

and which reflected IL-12 production in glomeruli [19]. Although there was no significant difference in the serum values of IL-12p70 between DPLN and MLN, significant difference was shown in the urinary value of IL-12p70. It was also demonstrated that the value of peripheral IFN- $\gamma / \mathrm{IL}-$ 4 ratio in DPLN was much greater than that in MLN, and these results are coincident with our previous report [20,21] (Figures 2 and 3). The fact that activity index for DPLN was correlated with the value of IFN- $\gamma /$ IL- 4 ratio indicates IFN- $\gamma$ plays a principal role in the development of DPLN [21]. It was also shown that large amounts of IL-18 have been found within serum and glomeruli of humans LN. However, there was no difference between them in DPLN and MLN [19].

MRL/MpJ-lpr/lpr (MRL/lpr) mice have proven particularly valuable for the investigation of SLE pathogenesis [22]. MRL/lpr mice develop a lupus-like autoimmune disease characterized by severe panisotypic hypergammaglobulinemia, autoantibody production, lymphadenopathy, and immune complex- (IC-)associated nephritis. Because $\mathrm{MLR} / \mathrm{lpr}$ nephritis involves the glomerulus, interstitium, and vascular components, and shows infiltration of macrophages and $\mathrm{T}$ cells, it is considered a suitable histological model for human DPLN. Moreover, like human DPLN, MLR/lpr nephritis is associated with Th1 responses [23]. MRL/lpr mice deficient in the IFN- $\gamma$ or its receptor developed significantly reduced DPLN $[24,25]$. IL-12 deficiency in MRL/lpr mice delayed DPLN and diminished systemic pathology [26]. It was also demonstrated that IL-18 accelerated DPLN, and that DPLN was exacerbated by the synergistic action of IL12 and IL-18, a combination known to promote Th1 cell development [27]. Th2 cytokine IL-10 deficient MRL/lpr mice developed severe DPLN [28]. These results indicate Th1-dependent mechanism plays a role in the pathogenesis of DPLN.

\section{Th2 Subset}

In human LN, MLN is a representative of secondary MGN. It was suggested a predominant Th2 cytokine response is associated with MGN pathogenesis $[21,29,30]$. The deposits stain uniformly with a predominance of IgG4 in idiopathic MGN [31, 32], and it was suggested that MGN occurs in individuals who generate $\operatorname{IgG} 4$ to M-type phospholipase A2 receptor (PLA2R) [33]. IgG4 is a Th2-dependent IgG subclass, and IL-4 directs naïve human B cells to switch to IgG4 and $\operatorname{IgE}$ production [34]. In addition the fact that chronic graft versus host diseases (cGVHD), in which Th2 immune response occurs predominantly, occasionally associates with MGN not diffuse proliferative glomerulonephritis (DPGN), supports the notion that predominant Th2 cytokine response is associated with MGN pathogenesis $[35,36]$. While MLN shows apparently different IgG subclass distribution of deposit [9], and IgG eluted from the glomerular deposits in the patient with MLN does not recognize PLA2R [33]. However, it was also suggested a predominant Th2 cytokine 


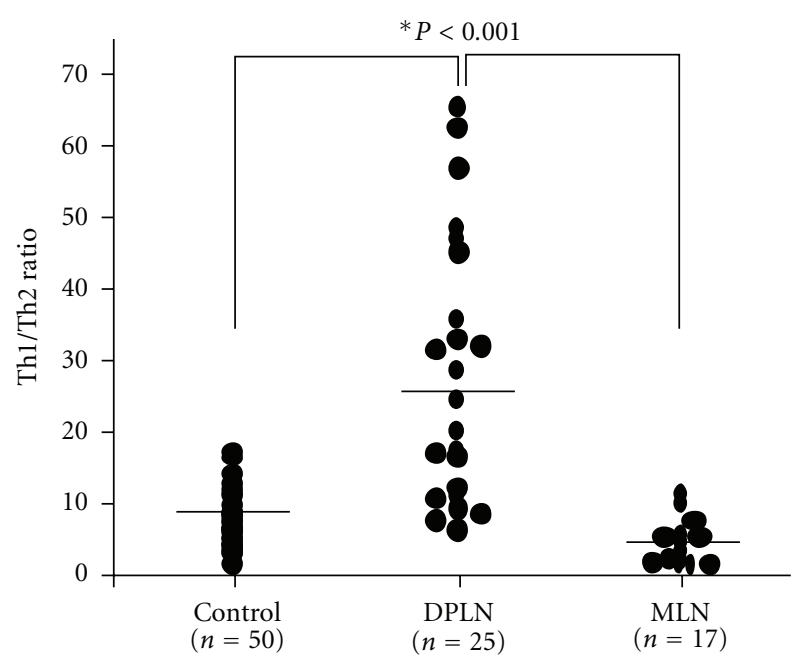

FIgURE 3: Distribution of the individual values of Th1/Th2 ratios in three groups control, DPLN, and MLN patients. Individual values of the ratio are plotted with the mean (bar) for each group, and (n) refers to the number of individuals in each group. The mean $\pm \mathrm{SD}$ values were as follows. Healthy normal control $8.82 \pm 4.45$, DPLN $25.89 \pm 18.98$, and MLN $4.66 \pm 4.64$, respectively. The value of DPLN was significantly higher than those of normal and MLN. $P$ values determined by Student's $t$-test.

response is associated with MLN pathogenesis [20, 29, 32]. Association study between MLN and IFN- $\gamma$ gene using microsatellite polymorphisms demonstrated that half of the MLN patients were homozygous of the allele of lower amount of IFN- $\gamma$ production. This result suggested that the immune response of SLE patient bearing lower amount of IFN- $\gamma$ production genotype is tend to be predominant to Th2. It was suggested that genetically determined IFN- $\gamma$ production should influence on the histological finding of LN [37].

In murine LN, MRL/lpr mice disrupted the WSX-1 gene developed disease essentially identical with human MLN, accompanied by marked impairment of Th1-type immune responses with Th2-type immune deviation [38] (Figure 4). WSX-1 is a class I cytokine receptor expressed mainly on $\mathrm{T}$ lymphocytes. The initial mounting of Th1 responses depends on the function of the WSX-1 gene, which encodes a subunit of the IL-27R with homology to IL-12R [39]. It is indicated that the phenotypic shift from DPLN to MLN in MRL/lpr mouse occurred because the loss of WSX-1 impaired the Th1 response and concomitantly enhanced the Th2 response. These results suggested that Th2-dependent mechanism plays a role in the pathogenesis of MLN.

\section{IL-17 Producing T Cells and Th17 Subset}

IL- 17 is mostly produced by $\mathrm{CD} 4^{+}, \mathrm{CD}^{+}, \mathrm{CD} 4^{-} / \mathrm{CD} 8^{-}$, and $\gamma / \delta$ T-cells, and Th17 cells. In human LN, it was reported that IL-17 expressing T-cells migrate to the kidney and contribute to inflammatory processes [40]. Expressions of costimulatory marker CD80 and CD134 on IL-17 producing $\mathrm{T}$ cells in the peripheral blood in SLE patients was increased as compared to healthy controls. The presence of CD134 ${ }^{+} \mathrm{T}-$ cells in the kidney suggests that these cells after ligation with CD134L expressed by endothelial cells migrate to the kidney and might contribute to inflammatory processes through IL-17 secretion. However, no significant difference in the expressions was seen between in patients with DPLN and MLN. In murine LN, relevant amounts of IL-17 are produced, and IL-17 producing T-cells largely infiltrate the nephritic kidneys of $\mathrm{NZB} / \mathrm{NZW}_{\mathrm{F} 1}$ mice [41]. By contrast, treatment with anti-CD3 monoclonal antibodies delayed the renal damage with concurrent defect of IL-17 production in both serum and glomeruli [42]. In MRL/lpr mice IL17 producing $\mathrm{T}$-cells arises from $\mathrm{CD}^{+} / \mathrm{CD}^{-} / \mathrm{CD}^{-}$subset. Therefore, this cell population is considered an active mediator of renal cytotoxicity.

IL-6 promotes the proliferation of renal mesangial cells and activates naïve $\mathrm{T}$ cell differentiation towards Th17 cooperated with transforming growth factor- $\beta$ (TGF- $\beta$ ) [43]. Also it primes the differentiation of $\mathrm{B}$ cells into antibodyproducing cells. In human LN, infiltrating inflammatory cells in the kidney, mainly macrophages and monocytes, are the main source of IL- 6 . In addition to the high IL-6 serum levels, significant overexpression of IL-6 is found in DPLN whereas healthy kidneys show little IL-6 expression [44]. In murine LN, blocking IL-6 with anti-IL-6 antibodies was able to reduce kidney pathology in MRL/lpr [45] and NZB/NZW mice [46] whereas mice with IL-6 overexpression develop mesangial proliferative glomerulonephritis [47]. IL-6-deficient MRL/lpr mice showed delayed onset of proteinuria and hematuria compared to control mice. The absence of IL- 6 resulted in significant reduction of infiltrating macrophages in the kidney, a decrease in renal IgG and $\mathrm{C} 3$ deposition, and a reduction of $\mathrm{CD} 4^{+}$and $\mathrm{CD} 8^{+}$ lymphocytes [48]. These results indicate that IL-6 is a strong promoter for DPLN.

\section{Treg Subset}

Treg cells are a heterogeneous population of $\mathrm{CD}^{+} /$ $\mathrm{CD}^{+} / \mathrm{CD} 25^{+}$cells differentiated in two subsets. The Foxp3 ${ }^{-}$ population includes both IL-10-producing Treg cells and Th3 cells that produce TGF- $\beta$. This cytokine plays crucial roles in the differentiation to $\mathrm{CD} 4^{+} \mathrm{CD} 25^{+} \mathrm{FoxP}^{+}$Treg. By contrast, Foxp $3^{+}$Treg cells play a protective role in autoimmunity. The expression of Foxp3 prevents T-cells from differentiating into Th17 proinflammatory effector Tcells [49]. On the other hand TGF- $\beta$, together with IL-6, promotes the differentiation of Th17 cells and suppresses FoxP3, leading to a reduction in Treg cells [43]. In human $\mathrm{LN}$, the proportion of Treg cells in PBMCs and serum and urinary TGF- $\beta 1$ levels were evaluated. TGF- $\beta 1$ is the main immunemodulating member of TGF- $\beta$ protein. The results demonstrated a significant decrease in the frequency of $\mathrm{CD} 4^{+} \mathrm{CD} 25^{\text {high }}$ and $\mathrm{CD} 4^{+} \mathrm{CD} 25^{+} \mathrm{FoxP}^{+} \mathrm{T}$ cells in $\mathrm{LN}$ patients. This decreased Treg cells might enhance autoimmune response. This decrease was accompanied with lower serum TGF- $\beta 1$ levels and higher urinary TGF- $\beta 1$ levels [50]. It was described that urinary TGF- $\beta$ reflects the grade of 


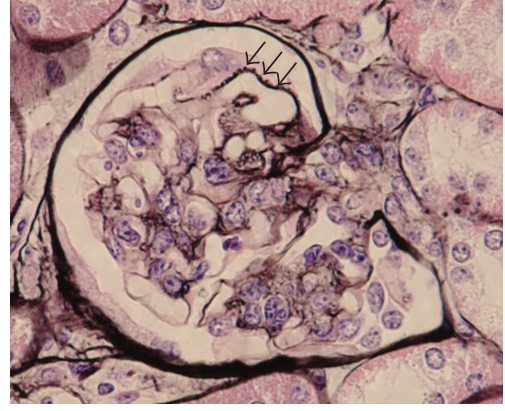

(a)

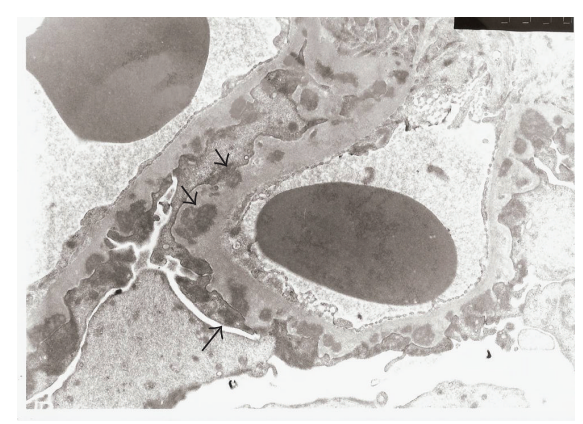

(b)

FIGURE 4: MRL/lpr mice disrupted the WSX-1 gene developed disease essentially identical with human MLN. (a) A representative glomerulus of 36-week-old WSX-1-/- MRL/lpr mouse (x400, PAM staining). Arrows indicate spike formation. (b) Electron micrograph (x4000) of the glomerular capillary of the mouse shows numerous subepithelial electron-dense deposits in the basement membrane (arrows).

interstitial fibrosis in glomerular disease and also the mesangial matrix increase in proliferative glomerulonephritis [51]. The elevated excretion of TGF- $\beta$ was also shown in the patient with focal glomerulosclerosis [52]. These results make us conceive the idea that Th17 cells and Treg cells may compete with each other in the process of development of LN, and nevertheless this Th17/Treg balance TGF- $\beta$ production may be activated.

In murine $\mathrm{LN}$, depletion of $\mathrm{CD} 4^{+} / \mathrm{CD} 25^{+}$cells in $\mathrm{NZB} / \mathrm{NZW}_{\mathrm{F} 1}$ accelerates the onset of DPLN whereas their transfer into CD4/CD25 KO mice delays the DPLN development [53]. The treatment of antimouse thymocyte globulin (ATG) in conjunction with TGF- $\beta 1$ for MRL/lpr mice demonstrated inhibition of progression of proteinuria and improvement in long-time survival accompanied with reduced renal histological findings. It was suggested that ATG followed TGF- $\beta 1$ treatment induced the differentiation for $\mathrm{CD}^{+}{ }^{+} \mathrm{CD} 25^{+} \mathrm{FoxP}^{+}$Treg [54].

Also IL-10 elevation occurs in different clinical conditions associated to SLE. Although this cytokine has been extensively studied, it remains unclear whether elevation of IL-10 is a cause of LN or not. Recently IL-10 is not considered as a lineage specific cytokine, because it has been shown that not only Th 2 cells but also Th 1 cells, Th17, and Treg cells can produce IL-10. We conceive that the overexpression of IL10 in SLE might reflect IL-10-producing Treg cells activation against intrinsic defect of the cytokine homeostasis.

\section{Conclusions}

It is interesting that there are two distinct phenotypes, DPLN and MLN, in histological findings of lupus nephritis despite of being based on the same disease. Although the determinants that account for these differences were still equivocal, recent studies have supported that Th1, IL-17 producing $\mathrm{T}$ cells and Th17 cells play a principal role for DPLN. While Th2 cells may contribute to development of MLN. Individual Th1/Th2 balance may be one of the critical determinants for histopathology of LN. Similarly Treg cells control effector $\mathrm{T}$ cells for maintenance of the immune response, and Treg/Th17 balance may be another determinant for development of LN.

\section{References}

[1] C. G. Cochrane and D. Koffler, "Immune complex disease in experimental animals and man," Advances in Immunology, vol. 16, no. C, pp. 185-264, 1973.

[2] B. L. Kotzin, "Systemic lupus erythematosus," Cell, vol. 85, no. 3, pp. 303-306, 1996.

[3] J. Churg, J. Bernstein, and R. J. Glassock, "Lupus nephritis," in Renal Disease: Classification and Atlas of Glomerular Disease, J. Churg, J. Bernstein, and R. J. Glassock, Eds., p. 151, IgakuShoin Medical, New York, NY, USA, 1995.

[4] F. J. Dixon, "The pathogenesis of glomerulonephritis," The American Journal of Medicine, vol. 44, no. 4, pp. 493-498, 1968.

[5] J. J. Weening, V. D. D’Agati, M. M. Schwartz et al., "The classification of glomerulonephritis in systemic lupus erythematosus revisited," Kidney International, vol. 65, no. 2, pp. 521-530, 2004.

[6] W. Lloyd and P. H. Schur, "Immune complexes, complement, and anti-DNA in exacerbations of systemic lupus erythematosus (SLE)," Medicine, vol. 60, no. 3, pp. 208-217, 1981.

[7] A. Valeri, J. Radhakrishnan, D. Estes et al., "Intravenous pulse cyclophosphamide treatment of severe lupus nephritis: a prospective five-year study," Clinical Nephrology, vol. 42, no. 2, pp. 71-78, 1994.

[8] R. Jefferis, J. Lund, and J. Pound, "Molecular definition of interaction sites on human IgG for Fc receptors (huFc $\gamma \mathrm{R}$ )," Molecular Immunology, vol. 27, no. 12, pp. 1237-1240, 1990.

[9] A. Kuroki, T. Shibata, H. Honda, D. Totsuka, K. Kobayashi, and T. Sugisaki, "Glomerular and serum IgG subclasses in diffuse proliferative lupus nephritis, and idiopathic membranous nephropathy," Internal Medicine, vol. 41, no. 11, pp. 936-942, 2002.

[10] T. R. Mosmann, H. Cherwinski, M. W. Bond, M. A. Giedlin, and R. L. Coffman, "Two types of murine helper T cell clone. I. Definition according to profiles of lymphokine activities and secreted proteins," The Journal of Immunology, vol. 136, no. 7, pp. 2348-2357, 1986.

[11] G. Del Prete, "The concept of type-1 and type-2 helper T cells and their cytokines in humans," International Reviews of Immunology, vol. 16, no. 3-4, pp. 427-455, 1998. 
[12] M. Funauchi, S. Ikoma, H. Enomoto, and A. Horiuchi, "Decreased Th1-like and increased Th2-like cells in systemic lupus erythematosus," Scandinavian Journal of Rheumatology, vol. 27, no. 3, pp. 219-224, 1998.

[13] V. R. Kelley and R. P. Wuthrich, "Cytokines in the pathogenesis of systemic lupus erythematosus," Seminars in Nephrology, vol. 19, no. 1, pp. 57-66, 1999.

[14] J. T. Chang, B. M. Segal, K. Nakanishi, H. Okamura, and E. M. Shevach, "The costimulatory effect of IL-18 on the induction of antigen-specific IFN- $\gamma$ production by resting T cells is IL12 dependent and is mediated by up-regulation of the IL-12 receptor $\beta 2$ subunit," European Journal of Immunology, vol. 30, no. 4, pp. 1113-1119, 2000.

[15] K. Masutani, M. Akahoshi, K. Tsuruya et al., "Predominance of Th1 immune response in diffuse proliferative lupus nephritis," Arthritis and Rheumatism, vol. 44, no. 9, pp. 2097-2106, 2001.

[16] S. Ashkar, G. F. Weber, V. Panoutsakopoulou et al., "Eta-1 (osteopontin): an early component of type-1 (cell-mediated) immunity," Science, vol. 287, no. 5454, pp. 860-864, 2000.

[17] A. W. O’Regan, J. M. Hayden, and J. S. Berman, "Osteopontin augments CD3-mediated interferon- $\gamma$ and CD40 ligand expression by $\mathrm{T}$ cells, which results in IL-12 production from peripheral blood mononuclear cells," Journal of Leukocyte Biology, vol. 68, no. 4, pp. 495-502, 2000.

[18] I. S. Grewal and R. A. Flavell, "CD40 and CD154 in cellmediated immunity," Annual Review of Immunology, vol. 16, pp. 111-135, 1998.

[19] M. Tucci, L. Lombardi, H. B. Richards, F. Dammacco, and F. Silvestris, "Overexpression of interleukin-12 and T helper 1 predominance in lupus nephritis," Clinical and Experimental Immunology, vol. 154, no. 2, pp. 247-254, 2008.

[20] M. Akahoshi, H. Nakashima, Y. Tanaka et al., "Th1/Th2 balance of peripheral T helper cells in systemic lupus erythematosus," Arthritis and Rheumatism, vol. 42, no. 8, pp. 1644$1648,1999$.

[21] K. Masutani, M. Taniguchi, H. Nakashima et al., "Upregulated interleukin- 4 production by peripheral T-helper cells in idiopathic membranous nephropathy," Nephrology Dialysis Transplantation, vol. 19, no. 3, pp. 580-586, 2004.

[22] A. N. Theofilopoulos and F. J. Dixon, "Murine models of systemic lupus erythematosus," Advances in Immunology, vol. 37, pp. 269-390, 1985.

[23] B. R. Lawson, G. J. Prud'homme, Y. Chang et al., "Treatment of murine lupus with cDNA encoding IFN $-\gamma \mathrm{R} / \mathrm{Fc}$," Journal of Clinical Investigation, vol. 106, no. 2, pp. 207-215, 2000.

[24] A. Schwarting, T. Wada, K. Kinoshita, G. Tesch, and V. R. Kelley, "IFN- $\gamma$ receptor signaling is essential for the initiation, acceleration, and destruction of autoimmune kidney disease in MRL-Fas(lpr) mice," Journal of Immunology, vol. 161, no. 1, pp. 494-503, 1998.

[25] C. Haas, B. Ryffel, and M. Le Hir, "IFN- $\gamma$ is essential for the development of autoimmune glomerulonephritis in MRL/lpr mice," Journal of Immunology, vol. 158, no. 11, pp. 5484-5491, 1997.

[26] E. Kikawada, D. M. Lenda, and V. R. Kelley, "IL-12 deficiency in MRL-Faslpr mice delays nephritis and intrarenal IFN- $\gamma$ expression, and diminishes systemic pathology," Journal of Immunology, vol. 170, no. 7, pp. 3915-3925, 2003.

[27] D. Robinson, K. Shibuya, A. Mui et al., "IGIF does not drive Th1 development but synergizes with IL-12 for interferon- $\gamma$ production and activates IRAK and NFkB," Immunity, vol. 7, no. 4, pp. 571-581, 1997.
[28] Z. Yin, G. Bahtiyar, N. Zhang et al., "IL-10 regulates murine lupus," Journal of Immunology, vol. 169, no. 4, pp. 2148-2155, 2002.

[29] D. B. G. Oliveira, "Membranous nephropathy: an IgG4mediated disease," The Lancet, vol. 351, no. 9103, pp. 670-671, 1998.

[30] A. Kuroki, M. Iyoda, T. Shibata, and T. Sugisaki, "Th2 cytokines increase and stimulate B cells to produce IgG4 in idiopathic membranous nephropathy," Kidney International, vol. 68, no. 1, pp. 302-310, 2005.

[31] M. Haas, "IgG subclass deposits in glomeruli of lupus and nonlupus membranous nephropathies," American Journal of Kidney Diseases, vol. 23, no. 3, pp. 358-364, 1994.

[32] H. Imai, K. Hamai, A. Komatsuda, H. Ohtani, and A. B. Miura, "IgG subclasses in patients with membranoproliferative glomerulonephritis, membranous nephropathy, and lupus nephritis," Kidney International, vol. 51, no. 1, pp. 270276, 1997.

[33] L. H. Beck, R. G. B. Bonegio, G. Lambeau et al., "M-type phospholipase A2 receptor as target antigen in idiopathic membranous nephropathy," The New England Journal of Medicine, vol. 361, no. 1, pp. 11-21, 2009.

[34] J. Punnonen, G. Aversa, B. G. Cocks et al., "Interleukin 13 induces interleukin 4-independent IgG4 and IgE synthesis and CD23 expression by human B cells," Proceedings of the National Academy of Sciences of the United States of America, vol. 90, no. 8, pp. 3730-3734, 1993.

[35] J. Lin, G. S. Markowitz, M. Nicolaides et al., "Membranous glomerulopathy associated with graft-versus-host disease following allogeneic stem cell transplantation: report of 2 cases and review of the literature," American Journal of Nephrology, vol. 21, no. 5, pp. 351-356, 2001.

[36] L. Rossi, F. Cardarelli, M. L. Vampa, C. Buzio, and G. Olivetti, "Membranous glomerulonephritis after haematopoietic cell transplantation for multiple myeloma," Nephron, vol. 88, no. 3, pp. 260-263, 2001.

[37] K. Miyake, H. Nakashima, M. Akahoshi et al., "Genetically determined interferon- $\gamma$ production influences the histological phenotype of lupus nephritis," Rheumatology, vol. 41, no. 5, pp. 518-524, 2002.

[38] S. Shimizu, N. Sugiyama, K. Masutani et al., "Membranous glomerulonephritis development with Th2-type immune deviations in MRL/lpr mice deficient for IL-27 receptor (WSX-1)," Journal of Immunology, vol. 175, no. 11, pp. 71857192, 2005.

[39] C. A. Sprecher, F. J. Grant, J. W. Baumgartner et al., "Cloning and characterization of a novel class I cytokine receptor," Biochemical and Biophysical Research Communications, vol. 246, no. 1, pp. 82-90, 1998.

[40] S. Dolff, D. Quandt, B. Wilde et al., "Increased expression of costimulatory markers CD134 and CD80 on interleukin-17 producing T cells in patients with systemic lupus erythematosus," Arthritis Research \& Therapy, p. R150, 2010.

[41] S. D. Fleming, M. Monestier, and G. C. Tsokos, "Accelerated ischemia/reperfusion-induced injury in autoimmunity-prone mice," Journal of Immunology, vol. 173, no. 6, pp. 4230-4235, 2004.

[42] H. Y. Wu, F. J. Quintana, and H. L. Weiner, "Nasal anti-CD3 antibody ameliorates lupus by inducing an IL-10-secreting $\mathrm{CD} 4+\mathrm{CD} 25-\mathrm{LAP}+$ regulatory $\mathrm{T}$ Cell and is associated with down-regulation of IL-17+CD4+ICOS +CXCR5+ follicular helper T cells," Journal of Immunology, vol. 181, no. 9, pp. 6038-6050, 2008. 
[43] P. R. Mangan, L. E. Harrington, D. B. O'Quinn et al., "Transforming growth factor- $\beta$ induces development of the $\mathrm{T}$ H17 lineage," Nature, vol. 441, no. 7090, pp. 231-234, 2006.

[44] T. Takemura, K. Yoshioka, K. Murakami et al., "Cellular localization of inflammatory cytokines in human glomerulonephritis," Virchows Archiv, vol. 424, no. 5, pp. 459-464, 1994.

[45] B. A. Kiberd, "Interleukin-6 receptor blockage ameliorates murine lupus nephritis," Journal of the American Society of Nephrology, vol. 4, no. 1, pp. 58-61, 1993.

[46] B. Liang, D. B. Gardner, D. E. Griswold, P. J. Bugelski, and X. Y. R. Song, "Anti-interleukin-6 monoclonal antibody inhibits autoimmune responses in a murine model of systemic lupus erythematosus," Immunology, vol. 119, no. 3, pp. 296-305, 2006.

[47] S. Suematsu, T. Matsusaka, T. Matsuda et al., "Generation of plasmacytomas with the chromosomal translocation $\mathrm{t}(12 ; 15)$ in interleukin 6 transgenic mice," Proceedings of the National Academy of Sciences of the United States of America, vol. 89, no. 1, pp. 232-235, 1992.

[48] H. Cash, M. Relle, J. Menke et al., "Interleukin 6 (IL-6) deficiency delays lupus nephritis in MRL-Fas lpr mice: the IL-6 pathway as a new therapeutic target in treatment of autoimmune kidney disease in systemic lupus erythematosus," Journal of Rheumatology, vol. 37, no. 1, pp. 60-70, 2010.

[49] D. A. Horwitz, S. G. Zheng, and J. D. Gray, "Natural and TGF$\beta$-induced Foxp3+CD4+ CD25+ regulatory $\mathrm{T}$ cells are not mirror images of each other," Trends in Immunology, vol. 29, no. 9, pp. 429-435, 2008.

[50] Q. Xing, H. Su, J. Cui, and B. Wang, "Role of treg cells and TGF-betal in patients with systemic lupus erythematosus: a possible relation with lupus nephritis," Immunological Investigations. In press.

[51] K. Murakami, T. Takemura, S. Hino, and K. Yoshioka, "Urinary transforming growth factor- $\beta$ in patients with glomerular diseases," Pediatric Nephrology, vol. 11, no. 3, pp. 334-336, 1997.

[52] H. Kanai, H. Mitsuhashi, K. Ono, S. Yano, and T. Naruse, "Increased excretion of urinary transforming growth factor beta in patients with focal glomerular sclerosis," Nephron, vol. 66, no. 4, pp. 391-395, 1994.

[53] S. G. Zheng, J. Wang, and D. A. Horwitz, "Cutting edge: Foxp3+ CD4+ CD25+ regulatory T cells induced by IL-2 and TGF- $\beta$ are resistant to Th17 conversion by IL-6," Journal of Immunology, vol. 180, no. 11, pp. 7112-7116, 2008.

[54] J. M. Kaplan, L. Woodworth, K. Smith, J. Coco, A. Vitsky, and J. M. McPherson, "Therapeutic benefit of treatment with antithymocyte globulin and latent TGF- $\beta 1$ in the MRL/lpr lupus mouse model," Lupus, vol. 17, no. 9, pp. 822-831, 2008. 


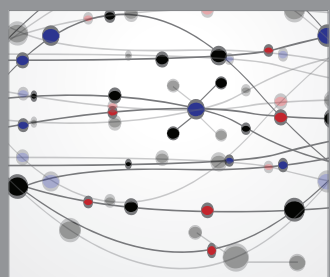

The Scientific World Journal
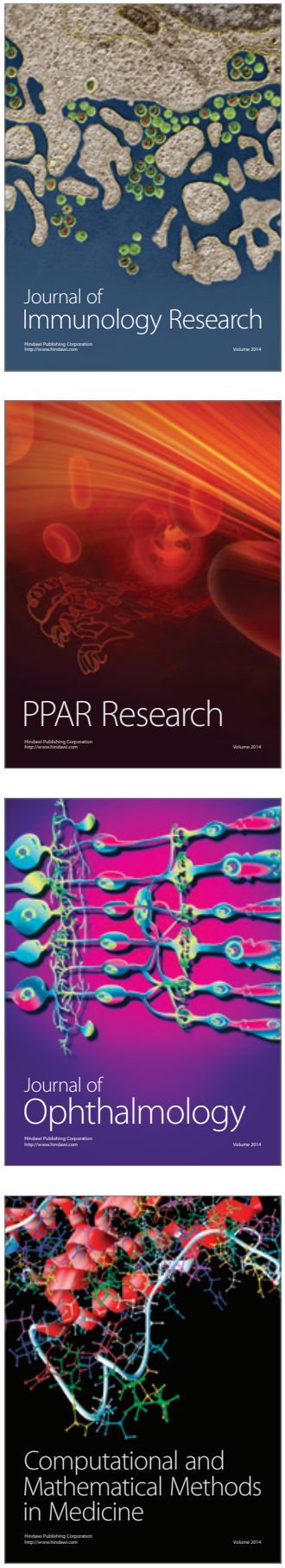

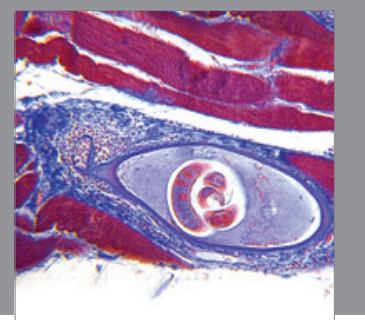

Gastroenterology

Research and Practice
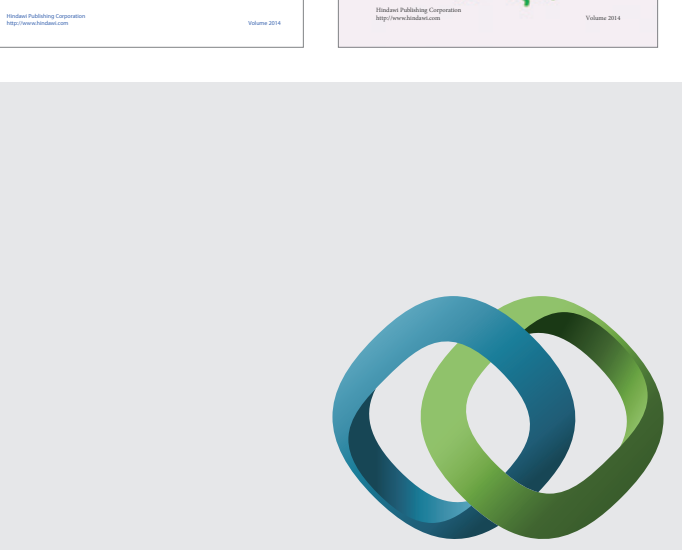

\section{Hindawi}

Submit your manuscripts at

http://www.hindawi.com
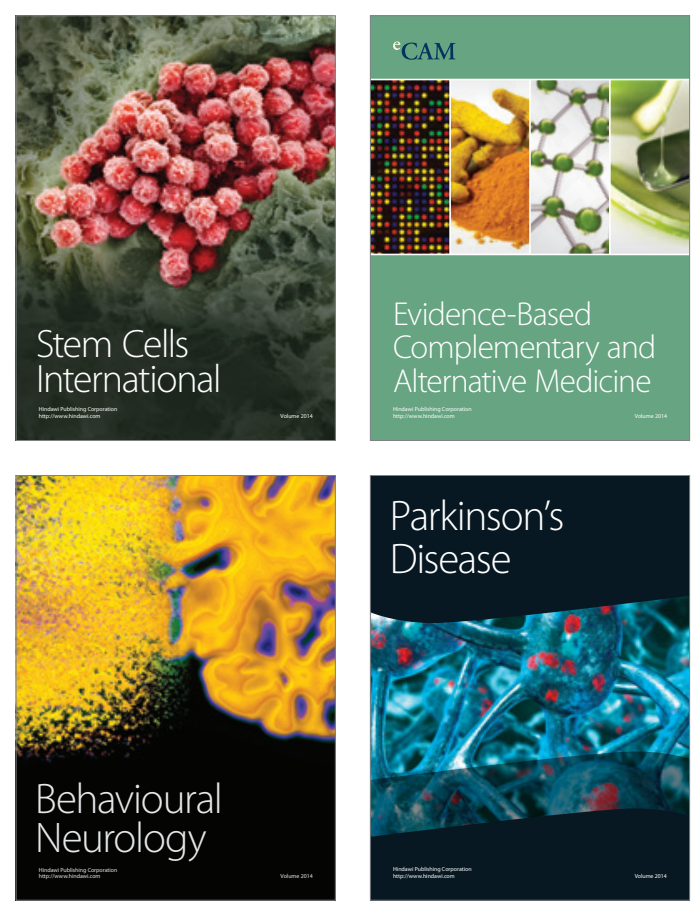

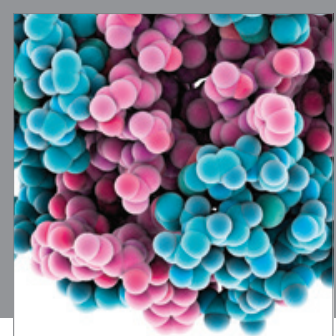

Journal of
Diabetes Research

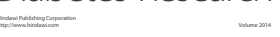

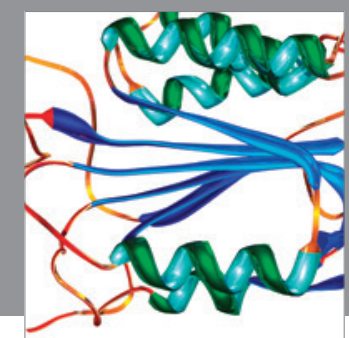

Disease Markers
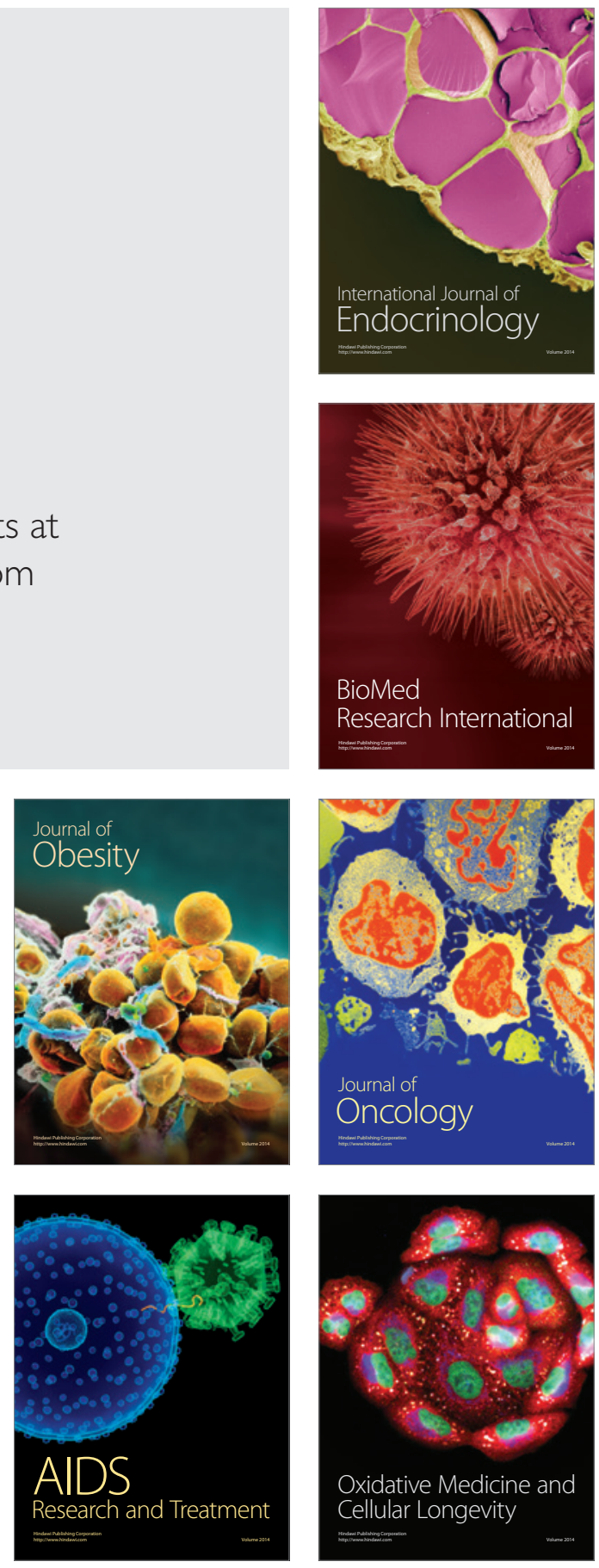